\title{
Neuropsychiatric symptoms and subsyndromes in patients with different stages of dementia in primary care follow-up (NeDEM project): a cross-sectional study.
}

\section{Victoria García-Martín ( $\square$ vgarcia@salud.madrid.org)}

Navalcarnero Health Care Center, Navalcarnero, Primary Care Management, Madrid Health Service. International Doctoral School. URJC. Madrid

\section{Canto de Hoyos-Alonso}

Pedro Laín Entralgo Health Care Center, Alcorcón, Primary Care Management, Madrid Health Service, Madrid

Gloria Ariza-Cardiel

Family and Community Medicine Teaching Unit Oeste, Primary Care Management, Madrid Health Service, Móstoles, Madrid

\section{Rosalía Delgado-Puebla}

Horta Healthcare Center, Barcelona, Primary Care Management, Catalonia Health Service, Catalonia

Paula García-Domingo

Alcorcón Foundation University Teaching Hospital, Madrid Health Service, Madrid

Erika Hernández-Melo

Navalcarnero Health Care Center, Navalcarnero, Primary Care Management, Madrid Health Service, Madrid

Javier López de Haro-de Torres

Villaviciosa de Odón Health Care Center, Villaviciosa de Odón, Primary Care Management, Madrid Health Service, Madrid

Isabel del Cura-González

Research Unit, Primary Care Management, Madrid Health Service. URJC. IiSGM. REDISSEC. Madrid

\section{Research Article}

Keywords: Dementia, Alzheimer's disease, Behavioural symptoms, Neuropsychiatric symptoms, Prevalence Subsyndromes, Primary care, Neuropsychiatric Inventory, Global Deterioration Scale, Psychological tests

Posted Date: September 1st, 2021

DOI: https://doi.org/10.21203/rs.3.rs-832449/v1

License: @ (i) This work is licensed under a Creative Commons Attribution 4.0 International License. Read Full License 


\section{Abstract}

\section{Background}

The objective was to describe the prevalence and intensity of Neuropsychiatric symptoms (NPSs) isolated and grouped into subsyndromes in patients with dementia in primary care (PC), to analyse their distribution based on stages of dementia and the relationship between them and the intensity of symptoms.

\section{Methods}

Design: Cross-sectional study. Setting and population: Patients with dementia, not institutionalized, in PC follow-up. Variables: Sociodemographic and clinical. Assessment instruments: The frequency and intensity of NPSs were measured with the Neuropsychiatric Inventory (NPI), and the stages of dementia with the Global Deterioration Scale (GDS). Statistical analysis: The number of NPSs per patient, mean NPI value, and prevalence and intensity of NPSs isolated and grouped into subsyndromes were calculated, as were their $95 \%$ Cls. The analyses were performed on an overall basis and by GDS. To analyse the association between NPI and GDS, multivariate analysis was performed with a generalized linear model.

Results

98.4\% (95\% Cl 94.5;99.8) of the patients presented some type of NPS, with an average of five symptoms per patient. The most frequent symptoms were apathy $[69.8 \%(95 \% \mathrm{Cl} 61.1 ; 77.5)]$, agitation $[55.8 \%(95 \% \mathrm{Cl} 46.8 ; 64.5)]$ and irritability $[48.8 \%(95 \% \mathrm{Cl} 39.9 ; 57.8)]$. The NPSs with greater intensity were apathy [NPI $3.2(95 \% \mathrm{Cl} 2.5 ; 3.8)$ ] and agitation [NPI $3.2(95 \% \mathrm{Cl} 2.5 ; 4.0)]$. For subsyndromes, hyperactivity predominated [86.0\% (95\% Cl 78.8;91.5)], followed by apathy [77.5\% (95\% Cl 69.3;84.4]). By phase of dementia, the most common isolated symptom was apathy $(60.7 \%-75.0 \%)$. Affective symptoms and irritability predominated in the initial stages, and psychotic symptoms predominated in advanced stages. The mean NPI score was $24.9(95 \% \mathrm{Cl} 21.5 ; 28.4)$ and increased from $15.6(95 \% \mathrm{Cl} 8.2 ; 23.1)$ for GDS 3 to 28.9 ( $95 \%$ Cl 12.6;45.1) for GDS 7. Patients with in the most advanced stages of dementia presented an NPI score of 7.6 $(95 \% \mathrm{Cl} 6.8 ; 8.3)$ points higher than mild dementia, adjusted for the other variables.

\section{Conclusions}

There is a high prevalence of NPSs in patients with dementia treated in PC. Symptoms change and increase in intensity as the disease progresses. Scales such as the NPI allow these symptoms to be identified, which could facilitate more stage-appropriate management.

\section{Background}

Dementia is a process that causes disability and dependency in the elderly, generating significant burdens on caregivers and a high cost for society that varies based on country and disease severity (1). Neuropsychiatric symptoms (NPSs) or behavioural and psychological symptoms of dementia (BPSDs) (2) are a series of symptoms related to altered perception, content of thought, mood and behaviour that can occur in people with dementia, constituting part of how the disease is expressed. Since 2011, NPSs have been considered, along with cognitive and functional impairment, a basic criterion in the diagnosis of dementia or major neurocognitive disorder (3).

NPSs can occur in 50-98\% of patients living in the community (4-15) and include depression, anxiety, apathy, agitation, irritability, continuous complaints, delusions, hallucinations, disinhibition and sleep or appetite disturbances, among others. They appear at any stage of the disease (16), even very early on $(4,10,14)$, varying in frequency and intensity based on the degree of cognitive impairment and the type of dementia $(11,17,18)$. Thus, compared with Alzheimer's disease, depression is more frequent in vascular dementia, and delusions and hallucinations are more frequent in Lewy body dementia, manifesting in earlier stages $(18,19)$. NPSs worsen the prognosis and accelerate the progression to severe dementia and even death $(20,21)$.

BPSDs also appear in patients with mild cognitive impairment $(\mathrm{MCl})$ more frequently $(43 \%)$ than in the general population. Their presence is considered a risk factor for $\mathrm{MCl}$ without dementia progressing to dementia (22), with an estimated annual transition rate of $25 \%(23)$.

In most patients, several of these symptoms can appear simultaneously, grouped into subgroups of symptoms or subsyndromes whose pathogenesis and management may be similar (2).

There are different scales to evaluate NPSs, in isolation, such as the Geriatric Depression Scale and scales to measure aggression or inappropriate sexual behaviour, or together, such as the Neuropsychiatric Inventory (NPI) (24), the Behavioural Pathology in Alzheimer's Disease Rating Scale (BEHAVE-AD) (25) and the Alzheimer's Disease Assessment Scale (ADAS) (26). 
There are few research studies on NPS conducted in the context of primary care (PC) $(6,27)$; however, it is at this level of care where most patients with dementia are treated throughout the disease process.

The main objective of this study was to describe the prevalence and intensity of NPSs isolated and grouped into subsyndromes in patients with dementia treated in PC and to analyse their distribution based on stages of dementia. As a secondary objective, the relationship between the stages of dementia and the intensity of symptoms, as measured by the NPI score, was analysed.

\section{Methods}

\section{Study design, setting and participants}

This was a cross-sectional descriptive observational study in two urban health centres in the municipalities of Alcorcón and Villaviciosa de Odón located in the western portion of the Community of Madrid (Spain); these municipalities have a combined registered population of 43,594 people, of whom 9,247 were $\geq 65$ years old. For the preparation of the article, the STROBE recommendations were followed (28).

Between November 1, 2015, and January 31, 2016, patients of all ages with a previous diagnosis of dementia identified with the International Classification of Primary Care (ICPC) code P70 and/or with specific treatment for dementia (anticholinesterase drugs (ATC code: N06D) and/or memantine (ATC code: N06DX01)) were selected from the electronic health records (EHRs) of the Community of Madrid (PC-Madrid). Eligible patients had a least one consultation or received PC in 2015 and had a known caregiver who agreed to participate in the study and signed the informed consent form. For patients with professional caregivers, informed consent was also requested from the legal representative of the patient. Informed consent was also requested from the patient himself or herself if considered able to do so at the discretion of the physician responsible. Institutionalized patients and/or patients with previous major mental disorders such as schizophrenia or other psychotic disorders were excluded, as well as those patients whose caregivers presented difficulties with language while conducting the interview and those who refused to participate in the study.

Based on these criteria, 129 patients were included in the study. With this sample size and considering an estimated prevalence of NPSs from $75-98 \%$, based on different published studies $(4,6,9,10,14)$, the estimation precision for our study was between $2.4 \%$ and $7.5 \%$.

Data collection was performed by reviewing the EHRs of the patients and interviewing primary caregivers.

\section{Variables and assessment instruments}

The following patient sociodemographic variables were collected: age, sex, highest level of education, type of coexistence and relationship between patient and caregiver. The following clinical variables were collected: duration of dementia, cognitive function and progression stage, functional assessment, presence of NPSs and treatment for dementia (specific and for NPSs). Reisberg's (29) Global Deterioration Scale (GDS) was used to classify the progression stage, where GDS 3 is mild cognitive decline and GDS 7 is very severe cognitive decline. For the analysis, the stages were grouped into mild (GDS 3 and 4), moderate (GDS 5) and severe (GDS 6 and 7) dementia. Functional assessment was performed using the Barthel index (30) with the levels of dependency established by Shah et al. (31). Dementia-specific treatment was considered if they had been prescribed anticholinesterase drugs (ATC code: N06D) and/or memantine (ATC code: N06DX01). The use of neuroleptics, antidepressants and/or benzodiazepines was assumed to be a possible symptomatic treatment for NPSs.

The frequency and severity of NPSs were measured with the Neuropsychiatric Inventory (NPI) (32). The NPI is a structured interview whose objective is to obtain information on the presence of psychological and behavioural symptoms in patients with Alzheimer's disease and other dementias. It explores the presence, in a preset period of time, usually the last month, of 10 different symptoms or subscales: delusions, hallucinations, agitation/aggressiveness, depression, anxiety, elation/euphoria, apathy/indifference, disinhibition, irritability/lability, and aberrant motor behaviour (NPI-10), to which sleep and nighttime behaviour disorders and appetite and eating disorders were added later (NPI-12) (https://eprovide.mapi-trust.org/instruments/neuropsychiatric-inventory-12-item-version). The NPI measures the frequency of each of these symptoms from 1 (less than once per week) to 4 (very frequently) and severity from 1 (produces little distress in the patient) to 3 (very disturbing to the patient and difficult to redirect). The score for each subscale is obtained from the product of the frequency and severity of each specific symptom. The total score is obtained by adding the value for all the subscales and ranges from 0 points (absence of neuropsychiatric disorder) to a maximum of 144 points. It has been validated in the Spanish population (33). Before data collection, the six researchers who conducted the interviews received prior information and training on the proper use of this tool. 
The symptoms detected with the NPI were divided into two groups based on whether they were significant (those whose intensity, that is, the product of frequency and severity, was $\geq 4$ ) or not significant (intensity score $<4$ ) (18)

In addition, the symptoms detected with the NPI were grouped into four subsyndromes or subgroups of symptoms based on the classification of Aalten et al. 2007 (2): "hyperactivity" (aggressiveness, disinhibition, irritability, aberrant motor behaviour and euphoria); "psychosis" (hallucinations, delusions and sleep disturbance); "Affective" (depression and anxiety) and "apathy" (apathy and appetite disturbance). The criterion used to define the presence of a subsyndrome was that the patient presented one or more of the symptoms that constituted the group; the presence of all symptoms of a subsyndrome simultaneously was not necessary.

\section{Statistical analysis}

A descriptive analysis of the sociodemographic and clinical characteristics of the included patients was performed. The qualitative variables are expressed as frequencies and percentages, and the quantitative variables are expressed as means and standard deviations or medians and interquartile ranges for data with a nonnormal distribution.

The prevalence of NPSs, the number of symptoms per patient and the mean value of the NPI based on sociodemographic and clinical characteristics were calculated, as were the $95 \%$ confidence intervals. The frequency, severity and intensity of NPSs were described, each separately and grouped into subsyndromes (2). Calculations were performed for all symptoms and for significant symptoms $(\mathrm{NPI}>$ or $=4)$ (18). In each GDS progression stage, the mean number of symptoms per patient, the mean value of the NPI and the frequency and intensity of each symptom and of each subsyndrome were analysed.

The association of sociodemographic and clinical variables with significant $(\mathrm{NPI} \geq 4)$ or nonsignificant $(\mathrm{NPI}<4)$ symptoms was assessed using the chi squared test, and associations with the NPI were measured as a total score using Student's t-test and ANOVA. To analyse the relationship between the NPI score (dependent variable) and the stages of dementia (mild, moderate and severe dementia), a generalized linear model (GLM) was constructed. As fit variables, sociodemographic variables (age, sex, and education) and clinical variables (duration, level of dependency based on the Barthel index, specific treatment for dementia, and treatment with neuroleptics, antidepressants and benzodiazepines) were included. This analysis tool was chosen because of its greater tolerance to not meeting the assumptions necessary to build classical models; GLMs can obtain unbiased estimators of associations in the presence of heteroscedasticity (34). Maximum likelihood methods were used for parameter estimations in the GLM, allowing us to obtain results without having to smooth the dependent variable and without the possible heteroscedasticity being problematic $(35,36)$. To avoid errors in the specification of the model, estimate errors were calculated by robust methods $(37,38)$, taking into account the inclusion of patients from different groups (health centres). To select the best model, the Akaike information criterion (AIC), Bayes information criteria (BIC) and the adjusted McFadden pseudo-R2 were studied (39). The improvement in BIC values was assessed based on the interpretations proposed by Kass and Raftery (40).

Statistical analyses were performed with SPSS version 26, STATA version 14 and R studio version 1.4.17.17.

\section{Ethics approval}

This study was conducted following the principles of the Declaration of Helsinki and its subsequent revisions and was approved by the Clinical Research Ethics Committee of Alcorcón Foundation University Hospital on September 23, 2015.

\section{Results}

Of the 356 patients identified with dementia (ICPC code P70 and/or use of specific treatment for dementia), 176 met the inclusion criteria and agreed to participate in the study. Figure 1 shows the flowchart for the study.

No significant differences were found in terms of sex and age between the participating patients and those who refused to participate or were not located. The mean age of the patients was 82.7 years (8), with a predominance of women $(70.5 \%)$. A total of $70.5 \%$ were older than 80 years, and only two patients were younger than 65 years. Regarding level of education, the majority (72.9\%) had primary education (34.1\% incomplete), $7.0 \%$ were illiterate, and a minority had higher education or university studies (2.4\%). The majority lived with a partner $(29.4 \%)$ or with other relatives, especially their children $(51.2 \%)$, and $13.2 \%$ of the patients lived with a professional caregiver. A total of $62.8 \%$ had more than 3 years of cognitive decline, and more than half $(52.7 \%)$ had severe or total functional dependency with respect to basic activities of daily living. Considering cognitive function and stage of progression of dementia, most patients (83.7\%) had a GDS score of 4, 5 or 6 (mild, moderate and severe dementia, respectively), with the initial (GDS 3) and final (GDS 7) stages being less represented. A total of $72.9 \%$ were under specific treatment for dementia with anticholinesterase drugs and/or 
memantine. Of the drugs used for NPSs, $48.1 \%$ were antidepressants, $42.6 \%$ were neuroleptics, and $35.7 \%$ were benzodiazepines. Table 1 shows the main characteristics of the patients who participated in the study.

Table 1 Sociodemographic and clinical characteristics of and NPI scores for patients with dementia included in the study 
Table 1 Sociodemographic and clinical characteristics of and NPI scores for patients with dementia included in the study.

$\begin{array}{ll}\mathrm{N}(\%) & \text { Total NPI score } \\ & \begin{array}{l}\text { Mean } \\ (\mathrm{SD})\end{array} \\ \end{array}$

Age

$<65$ years

$2(1.6 \%) \quad \begin{array}{lll}10.5 \\ (6.4)\end{array} \quad(-46.7 ; 67.7) \quad 0.709$

65-74 years

$21 \quad 26.2$

$(16.3 \%) \quad(23.0)$

75-79 years

$15 \quad 27.4$

$(11.6 \%) \quad(27.3)$

$\geq 80$ years

$91 \quad 24.6$

$(70.5 \%) \quad(18.0)$

$(15.8 ; 36.7)$

$(12.3 ; 42.5)$

$(20.8 ; 28.3)$

Sex

Men

38

$(29.5 \%)$

24.2

(21.8)

Women

$91 \quad 25.3$

$(70.5 \%) \quad(19.2)$

$(17.0 ; 31.4) \quad 0.782$

Women

$(70.5 \%)$

$(21.3 ; 29.2)$

Education

Illiterate

$9(7.0 \%) \quad 20.7$

(22.1)

$\begin{array}{ll}(3.7 ; 37.6) & 0.619\end{array}$

No education (less than 5 years)

$44 \quad 26.3$

(34.1\%) (19.5)

Primary education (more than 5 years, without completing mandatory education

to 16 years old)

$50 \quad 27.2$

(38.8\%) (20.7)

Secondary education, $7^{\text {th }}-10$ grade (EGB, ESO, elementary baccalaureate)

$17 \quad 21.6$

$(13.1 \%) \quad(20.4)$

$(11.1 ; 32.1)$

$6(4.6 \%) \quad 17.2$

(14.0)

$(2.4 ; 31.9)$

Baccalaureate, $11^{\text {th }}-12^{\text {th }}$ grade high school (post- 16 education)

$\begin{array}{ll}3(2.4 \%) & 14.0 \\ & (13.5)\end{array}$

$(-19.6 ; 47.6$

Higher education (vocational) and university

Habitation

Alone

$8(6.2 \%)$

19.3

(20.6)

$(2.0 ; 36.5) \quad 0.609$

With partner

$38 \quad 25.3$

$(29.4 \%) \quad(21.0)$

With family (with or without partner)

$66 \quad 24.1$

(51.2\%) (18.5)

With professional caregiver

$17 \quad 29.9$

(13.2\%) (23.1)

$(18.4 ; 32.2)$

$(19.6 ; 28.7)$

$(18.1 ; 41.8)$

GDS stage

GDS 3 (mild CD, borderline deterioration)

$8(6.2 \%) \quad 15.6$

(8.9)

$(8.2 ; 23.1) \quad 0.301$

GDS 4 (moderate CD, mild dementia)

$38 \quad 21.0$

(29.4\%) (16.6)

GDS 5 (moderately severe CD, moderate dementia)

\begin{tabular}{lll}
\hline 42 & 27.1 & $(20.1 ; 34.0)$ \\
$(32.6 \%)$ & $(22.3)$ & \\
\hline 28 & $\begin{array}{l}28.0 \\
(21.7 \%)\end{array}$ & $(20.9 ; 35.0)$ \\
\hline
\end{tabular}

GDS 6 (severe CD, moderately severe dementia)

$(15.5 ; 26.4)$

$(20.1 ; 34.0)$

$(20.9 ; 35.0)$

Page 6/21 
GDS 7 (very severe CD, severe dementia)

$13 \quad 28.9$

$(10.1 \%) \quad(26.9)$

$(12.6 ; 45.1)$

\section{Barthel index}

\begin{tabular}{|c|c|c|c|c|}
\hline Independent (100 points) & $\begin{array}{l}18 \\
(14.0 \%)\end{array}$ & $\begin{array}{l}14.7 \\
(14.0)\end{array}$ & $(7.8 ; 21.7)$ & 0.214 \\
\hline Slight dependency (91-99 points) & $6(4.6 \%)$ & $\begin{array}{l}22.7 \\
(27.5)\end{array}$ & $(-6.2 ; 51.5)$ & \\
\hline Moderate dependency (61-90 points) & $\begin{array}{l}37 \\
(28.7 \%)\end{array}$ & $\begin{array}{l}26.2 \\
(20.1)\end{array}$ & $(19.5 ; 33.0)$ & \\
\hline Severe dependency (21-60 points) & $\begin{array}{l}35 \\
(27.1 \%)\end{array}$ & $\begin{array}{l}27.0 \\
(17.6)\end{array}$ & $(21.0 ; 33.0)$ & \\
\hline Total dependency (<21 points) & $\begin{array}{l}33 \\
(25.6 \%)\end{array}$ & $\begin{array}{l}27.3 \\
(22.5)\end{array}$ & $(19.3 ; 35.2)$ & \\
\hline \multicolumn{5}{|l|}{ Duration of dementia } \\
\hline$\leq 1$ year & $9(7.0 \%)$ & $\begin{array}{l}30.8 \\
(25.3)\end{array}$ & $(11.3 ; 50.2)$ & \multirow[t]{5}{*}{0.736} \\
\hline $1-3$ years & $\begin{array}{l}39 \\
(30.2 \%)\end{array}$ & $\begin{array}{l}25.6 \\
(21.8)\end{array}$ & $(18.5 ; 32.7)$ & \\
\hline $3-6$ years & $\begin{array}{l}47 \\
(36.5 \%)\end{array}$ & $\begin{array}{l}23.0 \\
(15.4)\end{array}$ & $(18.4 ; 27.5)$ & \\
\hline $6-9$ years & $\begin{array}{l}15 \\
(11.6 \%)\end{array}$ & $\begin{array}{l}28.7 \\
(25.3)\end{array}$ & $(14.7 ; 42.7)$ & \\
\hline more than 9 years & $\begin{array}{l}19 \\
(14.7 \%)\end{array}$ & $\begin{array}{l}22.8 \\
(19.4)\end{array}$ & $(13.4 ; 32.2)$ & \\
\hline
\end{tabular}

Treatment

No specific treatment

$\begin{array}{llll}35 & 26.4 & (18,8 ; 34.0) & 0.613 \\ (27.1 \%) & (22.2) & & \\ 94 & 24.4 & (20.5 ; 28.3) & \\ (72.9 \%) & (19.1) & & \end{array}$

Treatment with neuroleptics

No

Specific treatment: CEI and/or memantine

(72.9\%)

No

$74 \quad 19.7$

(57.4\%) (16.5)

Yes

$\begin{array}{ll}55 & 31.9 \\ (42.6 \%) & (22.0)\end{array}$

Treatment with benzodiazepines

No

No

\begin{tabular}{|c|c|c|}
\hline $\begin{array}{l}83 \\
(64.3 \%)\end{array}$ & $\begin{array}{l}24.0 \\
(20.7)\end{array}$ & $(19.5 ; 28.5)$ \\
\hline $\begin{array}{l}46 \\
(35.7 \%)\end{array}$ & $\begin{array}{l}26.7 \\
(18.5)\end{array}$ & $(21.2 ; 32.2)$ \\
\hline
\end{tabular}

Treatment with antidepressants

\begin{tabular}{|c|c|c|c|}
\hline No & $\begin{array}{l}67 \\
(51.9 \%)\end{array}$ & $\begin{array}{l}21.3 \\
(17.7)\end{array}$ & $(17.0 ; 25.7)$ \\
\hline Yes & $\begin{array}{l}62 \\
(48.1 \%)\end{array}$ & $\begin{array}{l}28.8 \\
(21.5)\end{array}$ & $(23.4 ; 34.3)$ \\
\hline
\end{tabular}

NPI: Neuropsychiatric Inventory. GDS: Global Deterioration Scale. CD: cognitive decline. CEl: cholinesterase inhibitors.

A total of $98.4 \%(95 \% \mathrm{Cl} 94.5 ; 99.8)$ of the patients had some neuropsychiatric symptoms, and $84.5 \%(95 \% \mathrm{Cl} 77.1 ; 90.3)$ had at least one symptom of clinically significant intensity (NPI $\geq 4)$. 
The mean number of symptoms per patient was $5(95 \% \mathrm{Cl} 4.6 ; 5.5)$, decreasing to $3(95 \% \mathrm{Cl} 2.5 ; 3.3)$ when considering only symptoms of significant intensity. The mean total NPI score (per patient) was 24.9 (95\% Cl 21.5; 28.4), with a median of 21 (IQR: 10.8-34.0), with the highest scores for patients who were treated with neuroleptics or antidepressants $(p<0.05)$, drugs used for the treatment of these symptoms. [See Table 1 and Additional file 1].

A relationship was observed between the stage of dementia (GDS) and the NPI score, increasing by 7.6 points on average $(95 \% \mathrm{Cl} 6.8 ; 8.3)$ in the presence of severe dementia versus mild dementia, after adjusting for sex, age, duration of dementia, and treatment with neuroleptics and antidepressants [See Table 2].

Table 2

Relationship between the Neuropsychiatric Inventory (NPI) score and the stages of dementia based on the Global Deterioration Scale (GDS)

\begin{tabular}{|c|c|c|c|c|}
\hline Total NPI score & Coef & Robust Std. Err. & $\mathbf{p}$ & $95 \% \mathrm{Cl}$ \\
\hline \multicolumn{5}{|l|}{ Age } \\
\hline$<65$ years & \multicolumn{4}{|l|}{ ref } \\
\hline $65-74$ years & 9.64 & 1.09 & 0.000 & $7.50 ; 11.77$ \\
\hline $75-79$ years & 10.02 & 5.98 & 0.094 & $-1.70 ; 21.74$ \\
\hline$\geq 80$ years & 7.32 & 0.48 & 0.000 & $6.38 ; 8.26$ \\
\hline \multicolumn{5}{|l|}{ Sex (men/women) } \\
\hline Women & \multicolumn{4}{|l|}{ ref } \\
\hline Men & -0.42 & 2.96 & 0.887 & $-6.23 ; 5.39$ \\
\hline \multicolumn{5}{|l|}{ GDS stage } \\
\hline Mild dementia (GDS 3 and 4) & \multicolumn{4}{|l|}{ ref } \\
\hline Moderate dementia (GDS 5) & 8.30 & 5.78 & 0.151 & $-3.03 ; 19.64$ \\
\hline Severe dementia (GDS 6 and 7) & 7.58 & 0.38 & 0.000 & $6.83 ; 8.32$ \\
\hline \multicolumn{5}{|l|}{ Duration of dementia } \\
\hline$\leq 3$ years & \multicolumn{4}{|l|}{ ref } \\
\hline$>3$ years & -5.01 & 1.43 & 0.000 & $-7.81 ;-2,22$ \\
\hline \multicolumn{5}{|l|}{ Treatment with neuroleptics } \\
\hline No & \multicolumn{4}{|l|}{ ref } \\
\hline Yes & 11.22 & 5.07 & 0.027 & $1.29 ; 21.16$ \\
\hline \multicolumn{5}{|l|}{ Treatment with antidepressants } \\
\hline No & \multicolumn{4}{|l|}{ ref } \\
\hline Yes & 6.44 & 0.40 & 0.000 & $5.65 ; 7.22$ \\
\hline \multicolumn{5}{|c|}{ General linear model. Family: Gaussian. Linking function: identity. } \\
\hline \multicolumn{5}{|l|}{ BIC: 1118.30} \\
\hline \multicolumn{5}{|c|}{ McFadden pseudo-R2 adjusted: $15.5 \%$} \\
\hline NPI: Neuropsychiatric Inventory. & DS: Glol & Deterioration Sc & & \\
\hline
\end{tabular}


The most frequent symptom was apathy $[69.8 \%(95 \% \mathrm{Cl} 61.1 ; 77.5)]$, followed by agitation $[55.8 \%(95 \% \mathrm{Cl} 46.8 ; 64.5])$. The symptom intensity, calculated via frequency and severity, was greater for both apathy, with a mean of $3.2(95 \% \mathrm{Cl} 2.5 ; 3.8)$, and agitation, with a mean of 3.2 ( $95 \%$ IQ $2.5 ; 4.0)$, but the symptom that the caregivers considered the most serious and the most difficulty to manage was agitation [18.6\% (95\% Cl 12.3; 26.4)]. Euphoria was the least frequent [17.1\% (95\% Cl 11.0; 26.7)], lowest severity [1.6\% $(95 \% \mathrm{Cl} 0.2 ; 5.5)]$ and lowest intensity symptom $[0.5(95 \% \mathrm{Cl} 0.3 ; 0.8)]$. When considering only significant symptoms $(\mathrm{NPI} \geq 4)$, the most frequent were apathy $[37.2 \%(95 \% \mathrm{Cl} 28.9 ; 46.2)]$, irritability [34.9\% $(95 \% \mathrm{Cl} 26.7 ; 43.8)]$ and agitation $[34.1 \%(95 \% \mathrm{Cl} 26.0 ; 43.0)]$, and the highest intensity symptoms were agitation [8.4 (95\% Cl 7.5; 9.4)], sleep disorders [8.1 (95\% Cl 7.0; 9.3)] and hallucinations [7.8 $(95 \% \mathrm{Cl} 6.7 ; 8.9)]$ [See Fig. 2, Additional file 2 and Additional file 3].

When grouping symptoms by subsyndromes (2), the most common was hyperactivity both in overall frequency [86.0\% $(95 \% \mathrm{Cl} 78.8$; 91.5)] and in significant symptomatology [62.8\% (95\% Cl 53.8; 71.1)]. Psychotic and affective symptoms were presented in similar proportions ([66.7\% (95\% Cl 57.8; 74.7)] and [65.1\% (95\% Cl 56.2; 73.3)], respectively), although psychotic symptoms contributed to a greater proportion of significant symptoms [44.2\% (95\% Cl 35.4; 53.2)] [see Fig. 3 and Additional file 2]. When analysing the intensity of the subsyndromes, those with the highest mean value were hyperactivity $[9.4(95 \% \mathrm{Cl} 7.8 ; 11.0)]$ and psychosis $[6.5(95 \% \mathrm{Cl} 5.5 ; 8.1)]$ [see Additional file 3].

\section{Neuropsychiatric symptoms and subsyndromes based on the developmental stage of dementia}

Figure 4 shows the distribution of (the median) NPI in the different stages or phases of dementia based on the GDS classification. The mean NPI score for GDS 3 was 15.6 (95\% Cl 8.2; 23.1), and that for GDS 7 was 28.9 (95\% Cl 12.6; 45.1) [see Table 1 and Fig. 4].

When analysing the distribution of symptoms based on the stages of dementia, variation was observed as cognitive deterioration advanced. Apathy remained the most frequent symptom in all phases of the disease, occurring in $60.7-75.0 \%$ of patients. In early stages, depression, anxiety and irritability predominated, present in more than $50 \%$ of patients. Psychotic symptoms (delusions, hallucinations) were more common in more advanced stages, GDS 6 and 7. The intensity of the symptoms as deterioration progressed was also not homogeneous. Anxiety and depression remained more stable, while the intensity of apathy, hallucinations and delusions increased progressively throughout the disease. Statistical significance was only found for hallucinations [see Fig. 5, Fig. 6 and Additional file 4].

The distribution of clinically significant symptoms (NPI $\geq 4)$ in the different phases of dementia, in terms of frequency and intensity of symptoms, was similar to that described for the overall symptoms, and the trend was also only significant for hallucinations [See

\section{Additional file 5].}

When grouping by subsyndrome, the frequency of hyperactivity and apathy remained relatively stable throughout progression, with hyperactivity being the most frequent subsyndrome in all stages except in GDS 6, during which psychotic symptoms predominated [82.1\% $(95 \% \mathrm{Cl} 63.1 ; 93.9)]$. The affective subsyndrome was more common in mild [87.5\% (95\% $\mathrm{Cl} 47.3 ; 99.7)]$ or moderate cognitive decline [73.7\% (95\% Cl 56.9; 86.6)], and its frequency decreased as the disease progressed. For intensity, as the disease progressed, the mean value of the subsyndromes apathy and psychosis increased, with maximum values of $6.7(95 \% \mathrm{Cl} 2.5 ; 10.9)$ and $11(95 \% \mathrm{Cl} 3.4 ; 18.6)$, respectively, for GDS 7, the affective subsyndrome remained stable, and hyperactivity was more intense in intermediate phases, with values up to $11.2(95 \% \mathrm{Cl} 8.0 ; 14.5)$ for GDS 5 [see Fig. 7 and Additional file 6].

\section{Discussion}

The prevalence of NPSs found in our study was very high, tending to increase in the more advanced stages of dementia that present worse functionality and presenting changes in the distribution of different NPSs based on disease severity.

According to their caregivers, almost $100 \%$ of the patients presented some neuropsychiatric symptoms, and approximately $85 \%$ had at least one clinically significant symptom, that is, an NPI $\geq 4$. The prevalence results obtained in our study in noninstitutionalized patients are similar to those reported by other studies carried out in specialized clinics, with prevalence rates exceeding $90 \%$ (8-11), but higher than those reported for community-dwelling patients, with an overall NPS prevalence of $50-85 \%(5,6,12-14)$ and significant symptom prevalence of $40-67 \%(4,12,18,41)$. The higher prevalence of NPSs found can be explained because patients who had a previous diagnosis of dementia were included, unlike other studies that recruited patients by screening for dementia in the general population, possibly leading to a higher percentage of cases of mild dementia $(5,12)$. 
Our patients presented an average of five neuropsychiatric symptoms. Studies that have used the same 12-item version of the NPI have reported similar findings $(6,9)$. Apathy was the most frequent NPS, appearing in $70 \%$ of patients and being clinically relevant in almost $40 \%$. These data are consistent with those of other studies, with prevalence rates between 74 and $76 \%(9,42,43)$. Apathy stands out as the most common symptom in most publications $(8-10,14,15)$, but depression $(7,44-46)$, sleep (12) and appetite disturbances (13) have also been described as the most prevalent. These differences may be related to the baseline characteristics of the study population. Thus, depression predominated when there was a high percentage of mild $(7,45,46)$ or moderate $(44)$ dementia in patients. Although apathy was the most frequent symptom, agitation, sleep disorders and hallucinations were the most intense and had the greatest weight in the overall NPI score due to the impact they had on the patient and their caregivers.

The average total NPI score was 25 , without differences based on sex or age group, as was the case in other publications $(12,46)$. We also did not find differences based on level of education or level of dependency. Regarding coexistence, the NPI score was higher for patients who lived with a professional caregiver than for those who lived alone or with family (partner or other relatives). Although this association was not statistically significant, it reflects the reality of having to hire outside caregivers for individuals with a greater intensity of symptoms. The average NPI score was very similar to the scores reported in studies by Aalten et al. 2007 (2) (mean NPI 23) and GarcíaAlberca et al. 2008 (9) (mean NPI 27.9); in contrast, the mean score obtained herein was higher than the 12-15 points obtained by other authors, a difference that could be explained by different characteristics of the study populations, with a predominance of mild dementia, or the use of a 10-symptom version of the NPI instead of the NPI-12 $(27,44,46,47)$.

The NPI score (NPS intensity) tended to increase as the disease progressed, a relationship already described in other studies $(15,18,48$, 49). In our study, an increase of 7.6 points in the NPI was demonstrated between mild and advanced dementia after adjusting for sex, age and clinical factors that could influence this score, such as the duration of dementia and symptomatic treatment of NPS with neuroleptics or antidepressants. Regarding the distribution of symptoms based on the different stages, apathy was the most frequent in all stages. In the early stages (GDS 3), depression, anxiety, irritability and sleep disorders predominated, as observed in other studies in which symptoms were analysed in patients with mild cognitive decline or mild dementia $(10,14,15,45)$. Agitation became more frequent in stages GDS 4 and 5, which correspond to mild-moderate dementia, and psychotic symptoms (delusions and hallucinations) were more common in advanced stages (GDS 6 and 7), as observed in other studies $(15,42)$.

Changes in the frequency and intensity of NPSs as the disease progresses can be better observed by grouping symptoms into subsyndromes (2). The frequency of NPSs remained stable for the hyperactivity and apathy subsyndromes, decreased for the affective subsyndrome and increased for the psychotic subsyndrome. In contrast, intensity behaved differently, increasing both for the psychotic subsyndrome and for apathy throughout disease progression, and was more homogeneous for the affective and hyperactivity subsyndromes.

Numerous studies have grouped NPSs into subsyndromes $(13,15,21,27,45,47,50,51)$; however, few studies have examined their distribution based on GDS stage (52), especially in community-dwelling patients. This grouping by subsyndrome is of great interest from the clinical point of view, especially in a scenario of high frequency consultations, as happens in PC, because it allows simplification of the detection of NPSs and provides a more suitable approach with pharmacological or nonpharmacological measures based on the predominating symptom at any given time (53-56).

Among the limitations, it should be noted that although the size of our sample was small compared with population-based studies $(7,11$, $15,18,57)$, it is consistent with those in other studies performed in clinical practice $(8-10,14,27,41)$. One strength is that our entire eligible population was included as study subjects. We believe that our work with noninstitutionalized patients in PC follow-up allows a better approach for community-based patients than those approaches performed in neurology and geriatric consultations $(2,7-11,15,16$, $18,41)$ with more restrictive selection criteria or in institutionalized patients $(49,58)$ who have more advanced stages of dementia.

In our study, the cognitive level and stage of progression were determined using the GDS by questioning the caregiver. Interviewing or administering cognitive tests to the patient directly was not considered, following the recommendations of the Clinical Research Ethics Committee (CEIm), which suggests limiting patient distress as much as possible if interviewing the caregiver can answer the research question. When available, the Mini-mental State Examination (MMSE) was also used, but it was not included in the final analysis because these data were not available for all patients, and it was not essential for staging.

Unlike other studies that only included individuals with mild-moderate stages of dementia $(9,10,14)$ or that limited the age of inclusion $(6$, $7,12,13)$, in our study, we included patients at all stages of dementia of any age and with a diagnosis of dementia of any aetiology. We believe that this approach provides greater external validity to our results, although it may limit comparisons with other studies that only 
study Alzheimer's disease $(10,11,15,41)$ and/or the most frequent dementias $(7,18)$. For example, the wide dispersion of symptoms that we observed in advanced stages may be related to some patients who presented rapid-progression non-Alzheimer dementia.

Although patients in any stage of dementia were included, there was a low representation of the initial and final stages. The latter could have occurred because a high percentage of these individuals are treated in nursing homes, which usually occurs with more advanced dementias and/or with more intense symptoms. The lower representativeness of the initial stages could be explained by the usual delay in confirming the diagnosis from the onset of the first symptoms of dementia (59). Patients with memory deterioration or very mild cognitive decline could have early dementia but were not included, as only patients with confirmed dementia were included in the study.

This study is of interest because of the importance that these symptoms have in the management of the disease and the few studies on NPSs performed at this level of care $(6,27)$. NPSs condition the quality of life of the patient and caregiver and are one of the main reasons for PC consults by caregivers of patients with dementia. Knowing the frequency and intensity of the most significant symptoms and their course in the disease is crucial for patient management. However, in clinical practice, objective measurement instruments are not usually used to identify symptoms or to monitor treatment regimens. They are also not usually the object of research in PC, unlike the scales that measure cognitive symptoms (such as the MMSE) or function (such as the Barthel or Lawton activities of daily living scales), commonly used both in clinical practice and research. We believe that to improve the approach to these symptoms and the adequate care of patients and caregivers, it is essential to have a perspective from the reality of PC, reinforcing research in this field.

\section{Conclusions}

The prevalence of NPSs estimated with the NPI scale in noninstitutionalized patients with dementia in PC follow-up is high and changes based on the different progression stages of dementia, with an upward trend in the NPI score as dementia progresses. The most frequent and intense symptoms are apathy and agitation. As dementia progresses, the frequency of apathy is maintained, but its intensity increases. Psychotic symptoms (delusions, hallucinations) increase in frequency and intensity, and affective symptoms (depression, anxiety) decrease in frequency and maintain a similar intensity at all stages. The grouping of symptoms in subsyndromes (apathy, hyperactivity, psychotic and affective symptoms) helps to better illustrate the differences in the patterns of symptoms throughout the disease and can improve the guidance provided to caregivers regarding how to management their patient based on which subsyndrome predominates at each progression stage.

\section{Abbreviations}

ATC: Anatomical therapeutic chemical classification system

PC: Primary care

IC: Informed consent

ICPC: International classification of primary care

CD: Cognitive decline

EHR: Electronic health record

CEI: Cholinesterase inhibitor

GDS: Global Deterioration Scale

MMSE: Mini-Mental State Examination

NPI: Neuropsychiatric Inventory

P70: ICPC dementia code

BPSDs: Behavioural and psychological symptoms of dementia

NPSs: neuropsychiatric symptoms

STROBE: Strengthening the Reporting of OBservational Studies in Epidemiology

Page $11 / 21$ 


\section{Declarations}

\section{Ethics approval and consent to participate}

This study was conducted following the principles of the Declaration of Helsinki and its subsequent revisions and was approved by the Clinical Research Ethics Committee of Alcorcón Foundation University Hospital on September 23, 2015. Informed consent was requested from the caregivers responsible for the patient who agreed to the interview and, in the case of professional caregivers, the legal representative of the patient. It was also requested from those patients considered capable at the discretion of the responsible physician.

\section{Consent for publication}

Not applicable.

\section{Availability of data and materials}

The datasets used and/or analysed during the current study are available from the corresponding author on reasonable request.

All data generated or analysed during this study are included in this published article [and its supplementary information files].

\section{Competing interests}

The authors declare that they have no competing interests.

\section{Funding}

This project received a grant for the translation and publication of this paper from the Foundation for Biosanitary Research and Innovation in Primary Care (FIIBAP).

\section{Authors' contributions}

VG, MCH, GA, RD, PG, EH, and JL contributed to the conception of the study. VGM, MCH, GA and IDC contributed to the study design. VG, $\mathrm{MCH}, \mathrm{RD}, \mathrm{PG}, \mathrm{EH}$, and JL were responsible for data collection. VG, MCH and GA analysed and interpreted data. IDC also participated in the interpretation of data. VG and $\mathrm{MCH}$ wrote the first draft of the manuscript. IDC and GA revised the manuscript and provided substantive contributions to the manuscript. All authors read and approved the final manuscript.

\section{Acknowledgements}

- To Jesús Martín Fernández, Family and Community Medicine Teaching Unit Oeste, Primary Care Management, Madrid Health Service, Móstoles, Madrid, Spain, for his collaboration in the analysis with the general linear model.

\section{Authors' information (optional)}

Victoria García-Martín (ORCID: https://orcid.org/0000-0002-1560-9842)

- PhD student in Epidemiology and Public Health at Universidad Rey Juan Carlos (Rey Juan Carlos University), Madrid, Spain.

- Navalcarnero Health Care Center, Navalcarnero, Primary Care Management, Madrid Health Service, Madrid, Spain.

M Canto de Hoyos-Alonso (ORCID: https://orcid.org/0000-0002-1409-893X)

- Pedro Laín Entralgo Health Care Center, Alcorcón, Primary Care Management, Madrid Health Service, Madrid, Spain

Gloria Ariza-Cardiel

- Family and Community Medicine Teaching Unit Oeste, Primary Care Management, Madrid Health Service, Móstoles, Madrid, Spain.

Rosalía Delgado-Puebla

- Horta Healthcare Center, Barcelona, Primary Care Management, Catalonia Health Service, Catalonia, Spain.

Paula García-Domingo

Page 12/21 
- Alcorcón Foundation University Teaching Hospital, Madrid Health Service, Madrid, Spain

Erika Hernández-Melo

- Navalcarnero Health Care Center, Navalcarnero, Primary Care Management, Madrid Health Service, Madrid, Spain

Javier López de Haro-de Torres

- Villaviciosa de Odón Health Care Center, Villaviciosa de Odón, Primary Care Management, Madrid Health Service, Madrid, Spain

Isabel del Cura-González (ORCID IdCG: 0000-0002-3931-5304)

- Research Unit, Primary Care Management, Madrid Health Service, Madrid, Spain.

- Department of Medical Specialties and Public Health, Universidad Rey Juan Carlos (Rey Juan Carlos University), Alcorcón, Madrid, Spain.

- Health Services Research on Chronic Patients Network (REDISSEC) ISCIII, Madrid, Spain.

\section{References}

1. Nichols E, Szoeke CEl, Vollset SE, Abbasi N, Abd-Allah F, Abdela J, et al. Global, regional, and national burden of Alzheimer's disease and other dementias, 1990-2016: a systematic analysis for the Global Burden of Disease Study 2016. Lancet Neurol. 2019;18(1):88-106.

2. Aalten P, Verhey FRJ, Boziki M, Bullock R, Byrne EJ, Camus V, et al. Neuropsychiatric Syndromes in Dementia: Results from the European Alzheimer Disease Consortium - Part I. Dement Geriatr Cogn Disord. 2007;24(6):457-63.

3. McKhann GM, Knopman DS, Chertkow H, Hyman BT, Jack CR, Kawas CH, et al. The diagnosis of dementia due to Alzheimer's disease: Recommendations from the National Institute on Aging-Alzheimer's Association workgroups on diagnostic guidelines for Alzheimer's disease. Alzheimer's Dement. 2011;7(3):263-9.

4. Lyketsos CG, Lopez O, Jones B, Fitzpatrick AL, Breitner J, DeKosky S. Prevalence of Neuropsychiatric Symptoms in Dementia and Mild Cognitive Impairment. JAMA. 2002;288(12):1475.

5. Steinberg M, Tschanz JT, Corcoran C, Steffens DC, Norton MC, Lyketsos CG, et al. The persistence of neuropsychiatric symptoms in dementia: the Cache County Study. Int J Geriatr Psychiatry. 2004;19(1):19-26.

6. Thyrian JR, Eichler TS, Wucherer D, Dreier A, Teipel S, Hoffmann W. Behavioral and psychiatric symptoms in people with dementia in primary care. Alzheimer's Dement. 2014;10(4):611.

7. Liew TM. Symptom Clusters of Neuropsychiatric Symptoms in Mild Cognitive Impairment and Their Comparative Risks of Dementia: A Cohort Study of 8530 Older Persons. J Am Med Dir Assoc. 2019;20(8):1054.e1-1054.e9.

8. Petrovic M, Hurt C, Collins D, Burns A, Camus V, Liperoti R, et al. Clustering of behavioural and psychological symptoms in dementia (BPSD): A european alzheimer's disease consortium (EADC) study. Acta Clin Belg. 2007;62(6):426-32.

9. García-Alberca JM, Pablo Lara J, González-Barón S, Barbancho MA, Porta D, Berthier M. Prevalence and comorbidity of neuropsychiatric symptoms in Alzheimer's disease. Actas españolas Psiquiatr. 2008;36(5):265-70.

10. Abizanda P, López-Jiménez E, López-Ramos B, Romero L, Sánchez-Jurado PM, León M, et al. Síntomas psicológicos y conductuales en deterioro cognitivo leve y enfermedad de Alzheimer. Rev Esp Geriatr Gerontol. 2009;44(5):238-43.

11. Fernández M, Gobartt AL, Balañá M. Behavioural symptoms in patients with Alzheimer's disease and their association with cognitive impairment. BMC Neurol. 2010;10:87.

12. Haibo X, Shifu X, Tze Pin N, Chao C, Guorong M, Xuejue L, et al. Prevalence and severity of behavioral and psychological symptoms of dementia (BPSD) in community dwelling Chinese: Findings from the Shanghai three districts study. Aging Ment Heal. 2013;17(6):748-52.

13. Vaingankar JA, Chong SA, Abdin E, Picco L, Jeyagurunathan A, Seow E, et al. Behavioral and psychological symptoms of dementia: Prevalence, symptom groups and their correlates in community-based older adults with dementia in Singapore. Int Psychogeriatrics. 2017;29(8):1363-76.

14. Yatawara C, Hiu S, Tan L, Kandiah N. Neuropsychiatric symptoms in South-East Asian patients with mild cognitive impairment and dementia: prevalence, subtypes, and risk factors. Int J Geriatr Psychiatry. 2018;33(1):122-30. 
15. Siafarikas N, Selbaek G, Fladby T, Šaltyte Benth J, Auning E, Aarsland D. Frequency and subgroups of neuropsychiatric symptoms in mild cognitive impairment and different stages of dementia in Alzheimer's disease. Int Psychogeriatrics. 2018;30(1):103-13.

16. Benoit M, Robert PH, Staccini P, Brocker P, Guerin O, Lechowski L, et al. One-year longitudinal evaluation of neuropsychiatric symptoms in Alzheimer's disease. The REAL.FR Study. J Nutr Health Aging. 2005;9(2):95-9.

17. Benoit M, Staccini P, Brocker P, Benhamidat T, Bertogliati C, Lechowski L, et al. Symptômes comportementaux et psychologiques dans la maladie d'Alzheimer: Résultats de l'étude REAL.FR. Rev Med Interne. 2003;24(SUPPL. 3):319s-324s.

18. López-Pousa S, Vilalta-Franch J, Garre-Olmo J, Pons S, Cucurella MG. Characterisation and prevalence of the psychological and behavioural symptoms in patients with dementia. Rev Neurol. 2007;45(11):683-8.

19. Kazui H, Yoshiyama K, Kanemoto H, Suzuki Y, Sato S, Hashimoto M, et al. Differences of behavioral and psychological symptoms of dementia in disease severity in four major dementias. PLoS One. 2016;11(8).

20. Tun SM, Murman DL, Long HL, Colenda CC, Von Eye A. Predictive validity of neuropsychiatric subgroups on nursing home placement and survival in patients with alzheimer disease. Am J Geriatr Psychiatry. 2007;15(4):314-27.

21. Peters ME, Schwartz S, Han D, Rabins P V., Steinberg M, Tschanz JT, et al. Neuropsychiatric symptoms as predictors of progression to severe Alzheimer's dementia and death: The cache county dementia progression study. Am J Psychiatry. 2015;172(5):460-5.

22. Peters ME, Rosenberg PB, Steinberg M, Tschanz JT, Norton MC, Welsh-Bohmer KA, et al. Prevalence of neuropsychiatric symptoms in CIND and its subtypes: The cache county study. Am J Geriatr Psychiatry. 2012;20(5):416-24.

23. Rosenberg PB, Mielke MM, Appleby BS, Oh ES, Geda YE, Lyketsos CG. The association of neuropsychiatric symptoms in MCI with incident dementia and alzheimer disease. Am J Geriatr Psychiatry. 2013;21(7):685-95.

24. Cummings JL. The Neuropsychiatric Inventory: assessing psychopathology in dementia patients. Neurology. 1997;48(5 Suppl 6):S106.

25. Reisberg B, Borenstein J, Salob SP, Ferris SH, Franssen E, Georgotas A. Behavioral symptoms in Alzheimer's disease: Phenomenology and treatment. J Clin Psychiatry. 1987;48(5 SUPPL.):9-15.

26. Mohs RC, Rosen WG, Davis KL. The Alzheimer's disease assessment scale: An instrument for assessing treatment efficacy. Psychopharmacol Bull. 1983;19(3):448-50.

27. Borsje P, Lucassen PLBJ, Bor H, Wetzels RB, Pot AM, Koopmans RTCM. The course of neuropsychiatric symptoms in patients with dementia in primary care. Fam Pract. 2019;36(4):437-44.

28. Vandenbroucke JP, von Elm E, Altman DG, Gøtzsche PC, Mulrow CD, Pocock SJ, et al. Strengthening the Reporting of Observational Studies in Epidemiology (STROBE): Explanation and Elaboration. PLoS Med. 2007;4(10):e297.

29. Reisberg B, Ferris SH, De Leon MJ, Crook T. The global deterioration scale for assessment of primary degenerative dementia. Am J Psychiatry. 1982;139(9):1136-9.

30. Mahoney FI, Barthel DW. Functional evaluation: The Barthel Index. Md State Med J. 1965;14:61-5.

31. Shah S, Vanclay F, Cooper B. Improving the sensitivity of the Barthel Index for stroke rehabilitation. J Clin Epidemiol. 1989;42(8):7039.

32. Cummings JL, Mega M, Gray K, Rosenberg-Thompson S, Carusi DA, Gornbein J. The Neuropsychiatric Inventory: comprehensive assessment of psychopathology in dementia. Neurology. 1994;44(12):2308-14.

33. Vilalta-Franch, J, Lozano-Gallego, M, Hernández-Ferrándiz,M, Llinàs-Reglà,J, López-Pousa, S LO. Neuropsychiatric Inventory: propiedades psicométricas de su adaptación al español. Rev Neurol. 1999;29(1):15-9.

34. Jones AM. Models For Health Care. 2010.

35. Hardin J, Hilbe J. Generalized Linear Models and Extensions. Third Edit. College Station: Stata Press; 2012.

36. Blough DK, Madden CW, Hornbrook MC. Modeling risk using generalized linear models. J Health Econ. 1999;18(2):153-71.

37. Long JS, Ervin LH. Using Heteroscedasticity Consistent Standard Errors in the Linear Regression Model. Am Stat. 2000;54(3):217-24.

38. Wailoo AJ, Hernandez-Alava M, Manca A, Mejia A, Ray J, Crawford B, et al. Mapping to Estimate Health-State Utility from NonPreference-Based Outcome Measures: An ISPOR Good Practices for Outcomes Research Task Force Report. Value Heal. 2017;20(1):18-27.

39. Shtatland ES, Kleinman K, Cain EM. One More Time About R2 Measures of Fit in Logistic Regression. NESUG 15 Proc. 2002; (15):222-6.

40. Kass RE, Raftery AE. Bayes Factors. J Am Stat Assoc. 1995 Jun;90(430):773-95. 
41. Gonfrier S, Andrieu S, Renaud D, Vellas B, Robert PH. Course of neuropsychiatric symptoms during a 4-year follow up in the REAL-FR cohort. J Nutr Health Aging. 2012;16(2):134-7.

42. Craig D, Mirakhur A, Hart DJ, Mcllroy SP, Passmore AP. A cross-sectional study of neuropsychiatric symptoms in 435 patients with Alzheimer's disease. Am J Geriatr Psychiatry. 2005;13(6):460-8.

43. Mirakhur A, Craig D, Hart DJ, Mcllroy SP, Passmore AP. Behavioural and psychological syndromes in Alzheimer's disease. Int J Geriatr Psychiatry. 2004;19(11):1035-9.

44. Kang HS, Ahn IS, Kim JH, Kim DK. Neuropsychiatric symptoms in Korean patients with Alzheimer's disease: Exploratory factor analysis and confirmatory factor analysis of the neuropsychiatric inventory. Dement Geriatr Cogn Disord. 2010;29:82-7.

45. Acosta-Castillo GI, Luisa Sosa A, Orozco R, Borges G, Velasco Suárez M. Síntomas neuropsiquiátricos en adultos mayores con demencia y su relación con la severidad de la enfermedad. Rev Investig Clínica. 2012;64(4):354-63.

46. Thyrian JR, Eichler T, Hertel J, Wucherer D, Dreier A, Michalowsky B, et al. Burden of behavioral and psychiatric symptoms in people screened positive for dementia in primary care: Results of the DelpHi-study. J Alzheimer's Dis. 2015;46(2):451-9.

47. Spalletta G, Musicco M, Padovani A, Rozzini L, Perri R, Fadda L, et al. Neuropsychiatric Symptoms and Syndromes in a Large Cohort of Newly Diagnosed, Untreated Patients With Alzheimer Disease. Am J Geriatr Psychiatry. 2010;18:11.

48. Fernandez-Martinez M, Molano A, Castro J, Zarranz JJ. Prevalence of Neuropsychiatric Symptoms in Mild Cognitive Impairment and Alzheimer's Disease, and its Relationship with Cognitive Impairment. Curr Alzheimer Res. 2010;999(999):1-10.

49. Robles Castiñeiras A, Díaz Grávalos GJ, Reinoso Hermida S, López González A, Vázquez Gil C, García Caballero AA. Prevalencia de síntomas neuropsiquiátricos en pacientes institucionalizados con diagnóstico de demencia y factores asociados: Estudio transversal multicéntrico. Rev Esp Geriatr Gerontol. 2012;47(3):96-101.

50. Truzzi A, Ulstein I, Valente L, Engelhardt E, Freire Coutinho ES, Laks J, et al. Patterns of neuropsychiatric sub-syndromes in Brazilian and Norwegian patients with dementia. Int Psychogeriatrics. 2013;25(2):228-35.

51. Regier NG, Hodgson NA, Gitlin LN. Neuropsychiatric symptom profiles of community-dwelling persons living with dementia: Factor structures revisited. Int J Geriatr Psychiatry. 2020;35(9):1009-20.

52. Zuidema SU, De Jonghe JFM, Verhey FRJ, Koopmans RTCM. Neuropsychiatric symptoms in nursing home patients: Factor structure invariance of the Dutch nursing home version of the neuropsychiatric inventory in different stages of dementia. Dement Geriatr Cogn Disord. 2007;24(3):169-76.

53. Kales HC, Lyketsos CG, Miller EM, Ballard C. Management of behavioral and psychological symptoms in people with Alzheimer's disease: An international Delphi consensus. Int Psychogeriatrics. 2019;31(1):83-90.

54. Abraha I, Rimland JM, Trotta FM, Dell'Aquila G, Cruz-Jentoft A, Petrovic M, et al. Systematic review of systematic reviews of nonpharmacological interventions to treat behavioural disturbances in older patients with dementia. the SENATOR-OnTop series. BMJ Open. 2017;7(3):12759.

55. Caspar S, Davis ED, Douziech A, Scott DR. Nonpharmacological Management of Behavioral and Psychological Symptoms of Dementia: What Works, in What Circumstances, and Why? Innov Aging. 2017;1(3):1-10.

56. Magierski R, Sobow T, Schwertner E, Religa D. Pharmacotherapy of Behavioral and Psychological Symptoms of Dementia: State of the Art and Future Progress. Front Pharmacol. 2020;11:1168.

57. Gerritsen AAJ, Bakker C, Verhey FRJ, de Vugt ME, Melis RJF, Koopmans RTCM, et al. Prevalence of Comorbidity in Patients With Young-Onset Alzheimer Disease Compared With Late-Onset: A Comparative Cohort Study. J Am Med Dir Assoc. 2016;

58. Zuidema SU, Derksen E, Verhey FRJ, Koopmans RTCM. Prevalence of neuropsychiatric symptoms in a large sample of Dutch nursing home patients with dementia. Int J Geriatr Psychiatry. 2007;22(7):632-8.

59. Aldus CF, Arthur A, Dennington-Price A, Millac P, Richmond P, Dening T, et al. Undiagnosed dementia in primary care: a record linkage study. Heal Serv Deliv Res. 2020;8(20):1-108.

\section{Figures}




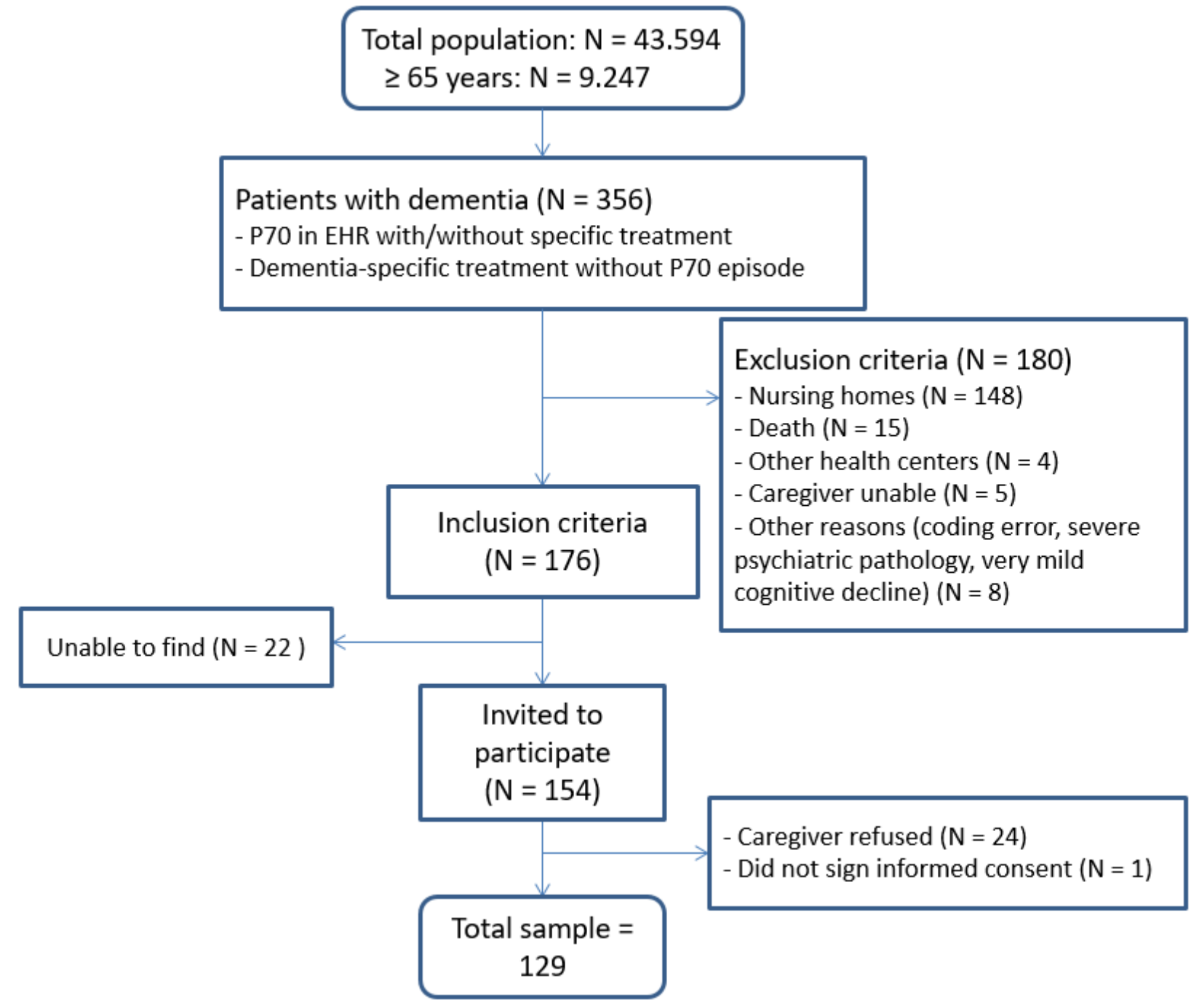

Figure 1

Study flowchart Legend: P70: ICPC code (International Classification of Primary Care). EHRs: electronic health records. IC: informed consent. 


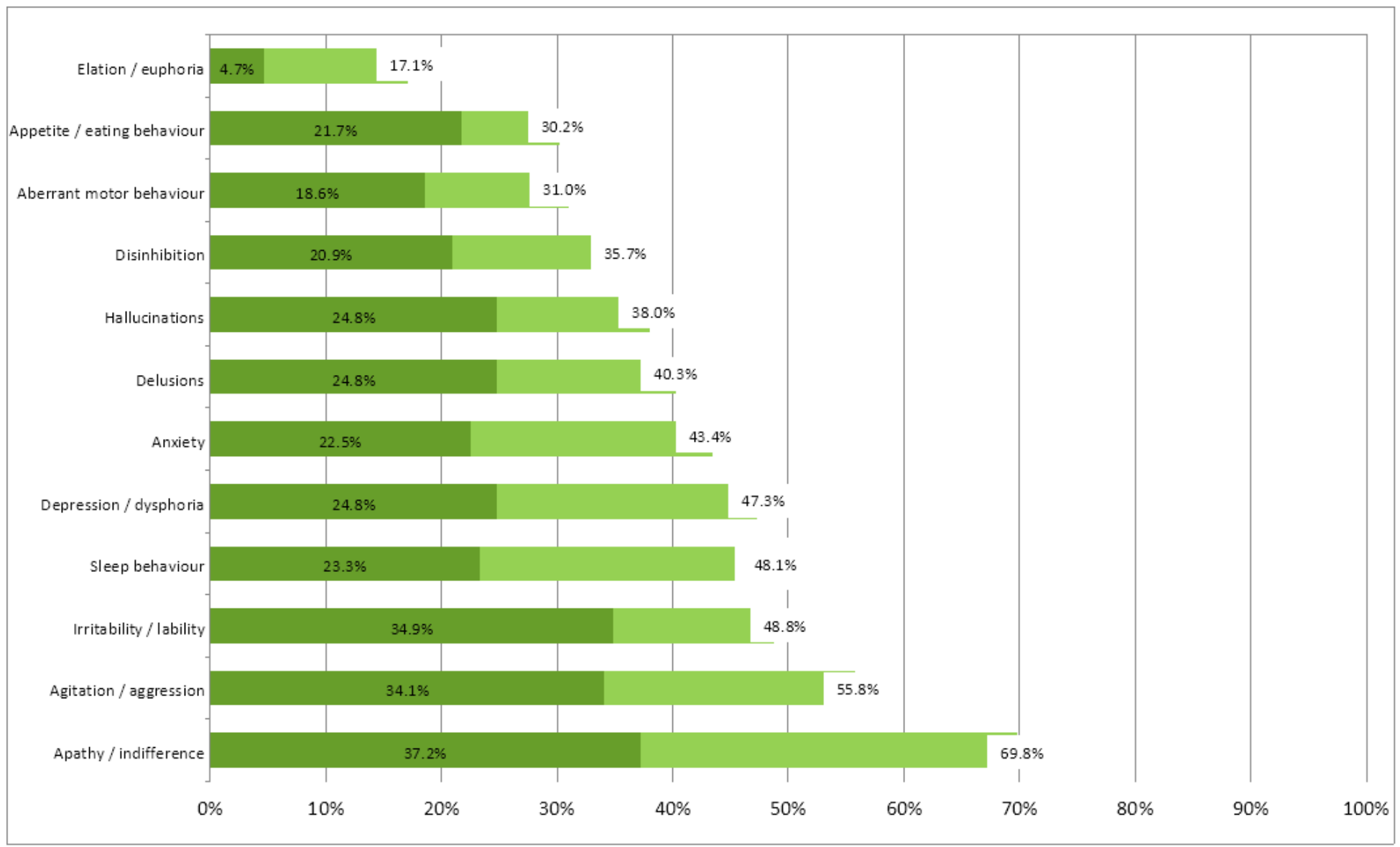

\section{Figure 2}

Prevalence of neuropsychiatric symptoms, in total and with clinically significant symptoms (NPI $\geq 4$ ), in patients with dementia included in the study Legend: Light bars represent the prevalence of total symptoms, and dark bars the prevalence of clinically significant symptoms (those with an NPI frequency by severity score $\geq 4$ ).

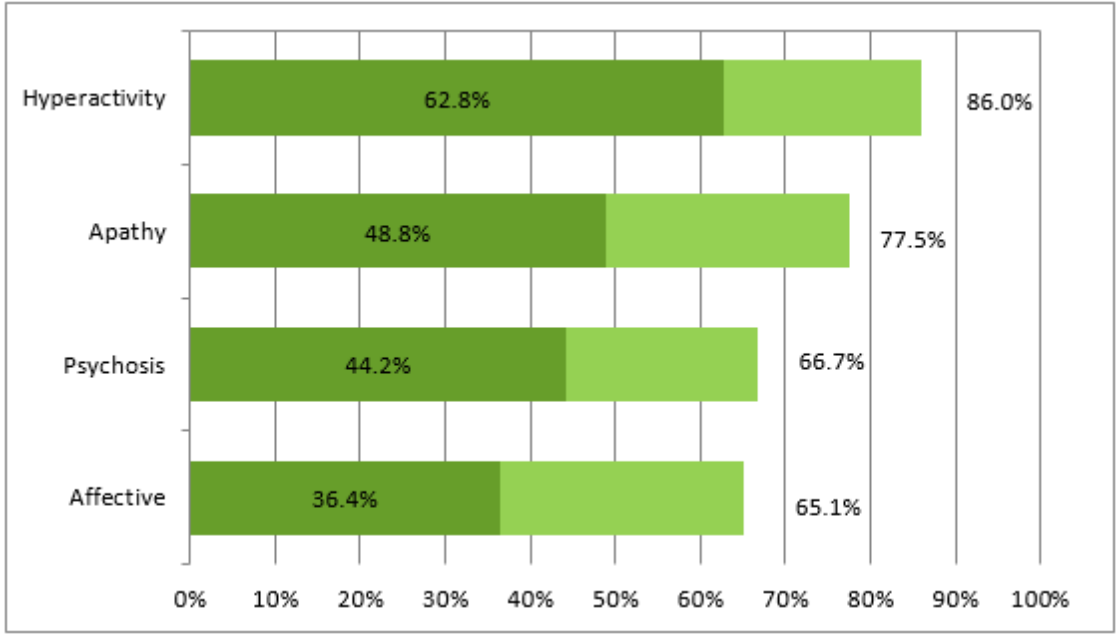

\section{Figure 3}

Frequency of neuropsychiatric subsyndromes, in total and with clinically significant symptoms (NPI $\geq 4$ ), in patients with dementia included in the study Legend: Hyperactivity subsyndrome: aggressiveness, disinhibition, irritability, aberrant motor behaviour and euphoria. Apathy subsyndrome: apathy and appetite disorders. Psychosis subsyndrome: hallucinations, delusions and sleep disorders. Affective subsyndrome: depression and anxiety. Light bars represent the prevalence of subsyndromes with total symptoms, and dark bars represent those with clinically significant symptoms (those with an NPI frequency by severity score $\geq 4$ ). 


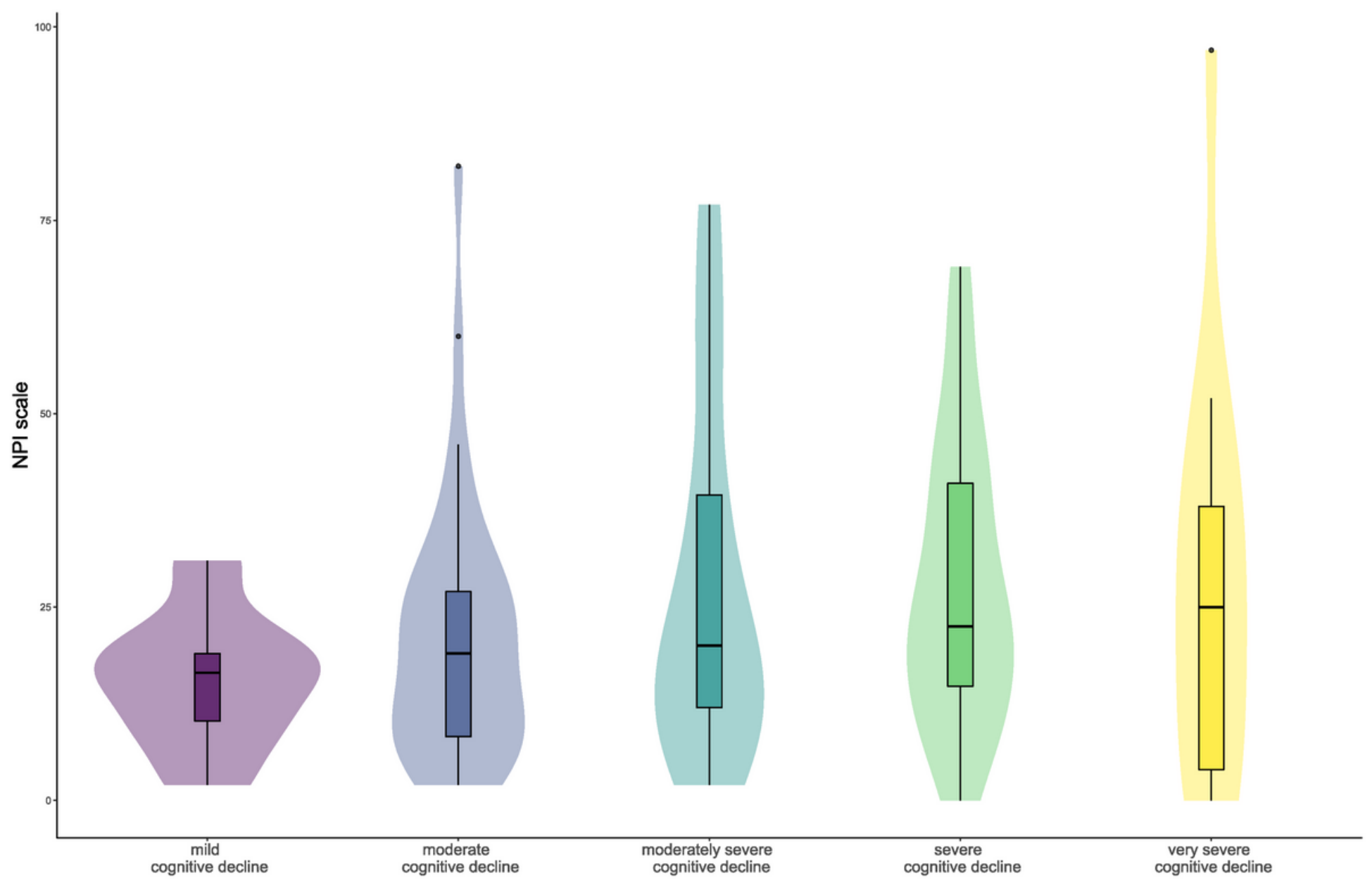

Figure 4

Mean NPI score based on dementia progression (GDS stage) 


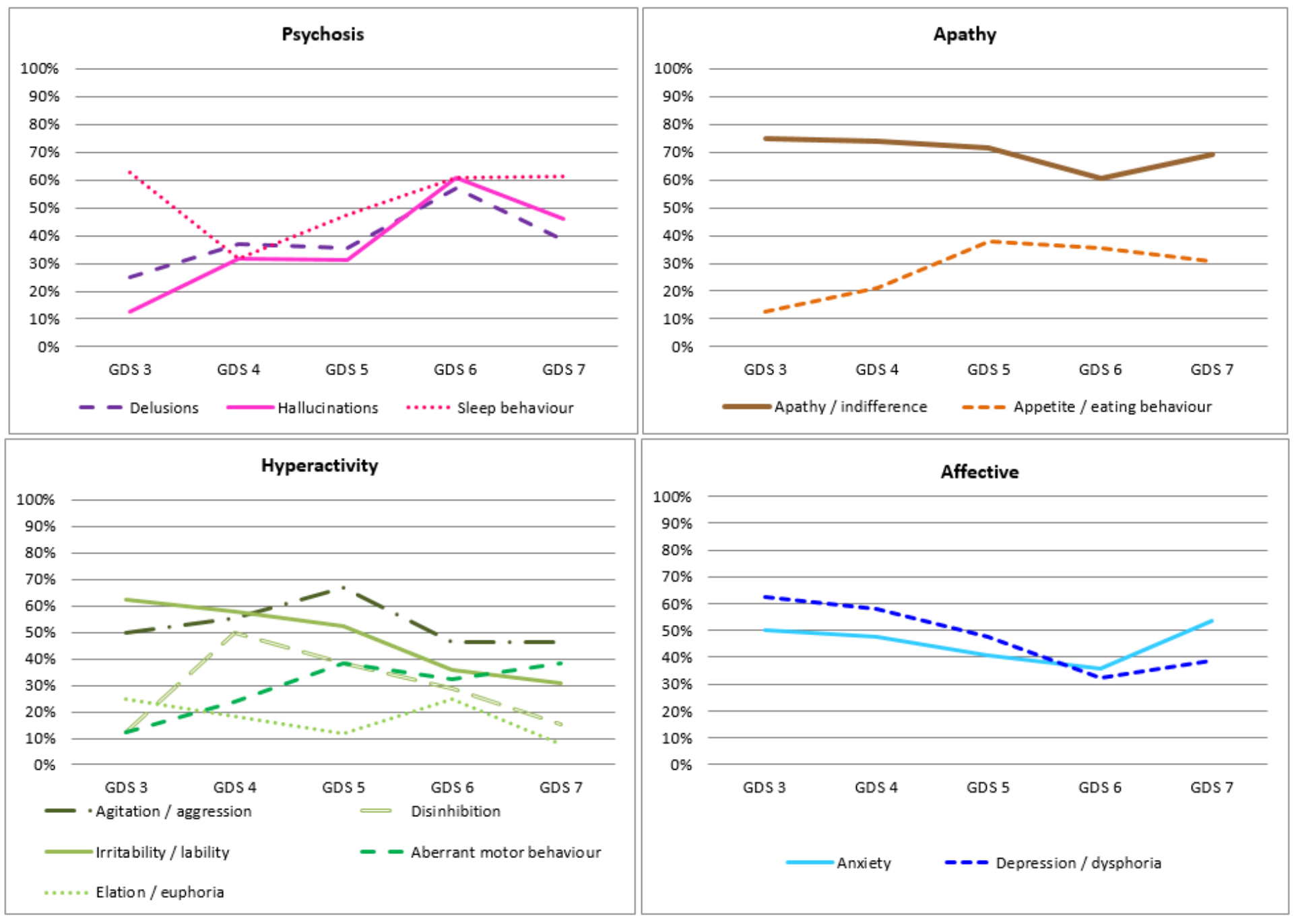

Figure 5

Frequency of neuropsychiatric symptoms based on dementia progression (GDS stage) grouped by subsyndromes (2) Legend: GDS: Global Deterioration Scale 

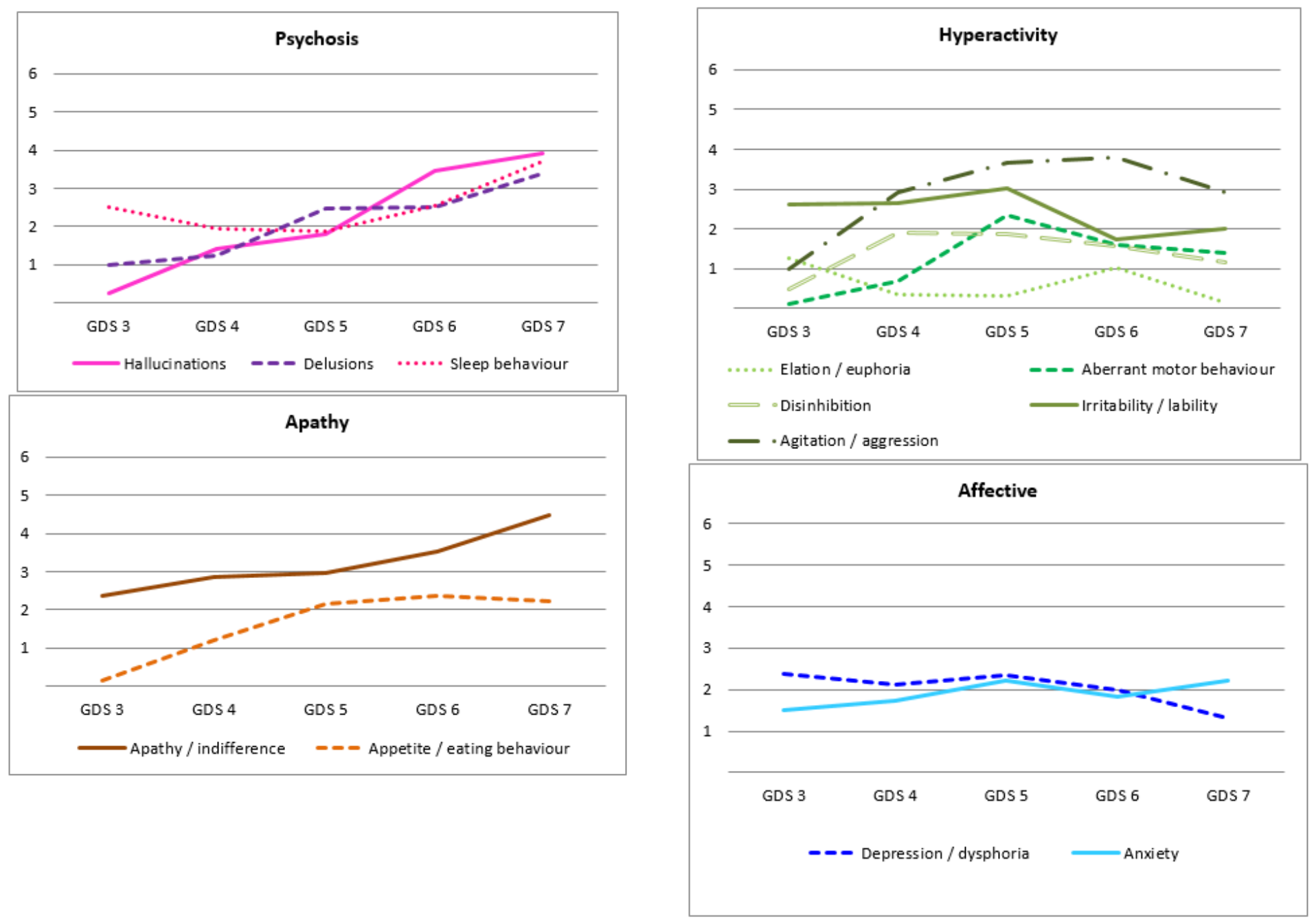

\section{Figure 6}

Intensity of neuropsychiatric symptoms in each developmental stage of dementia (GDS) grouped by subsyndromes (2) Legend: Intensity: average frequency and severity score for each symptom. Range of 0 to 12 for all symptoms. GDS: Global Deterioration Scale

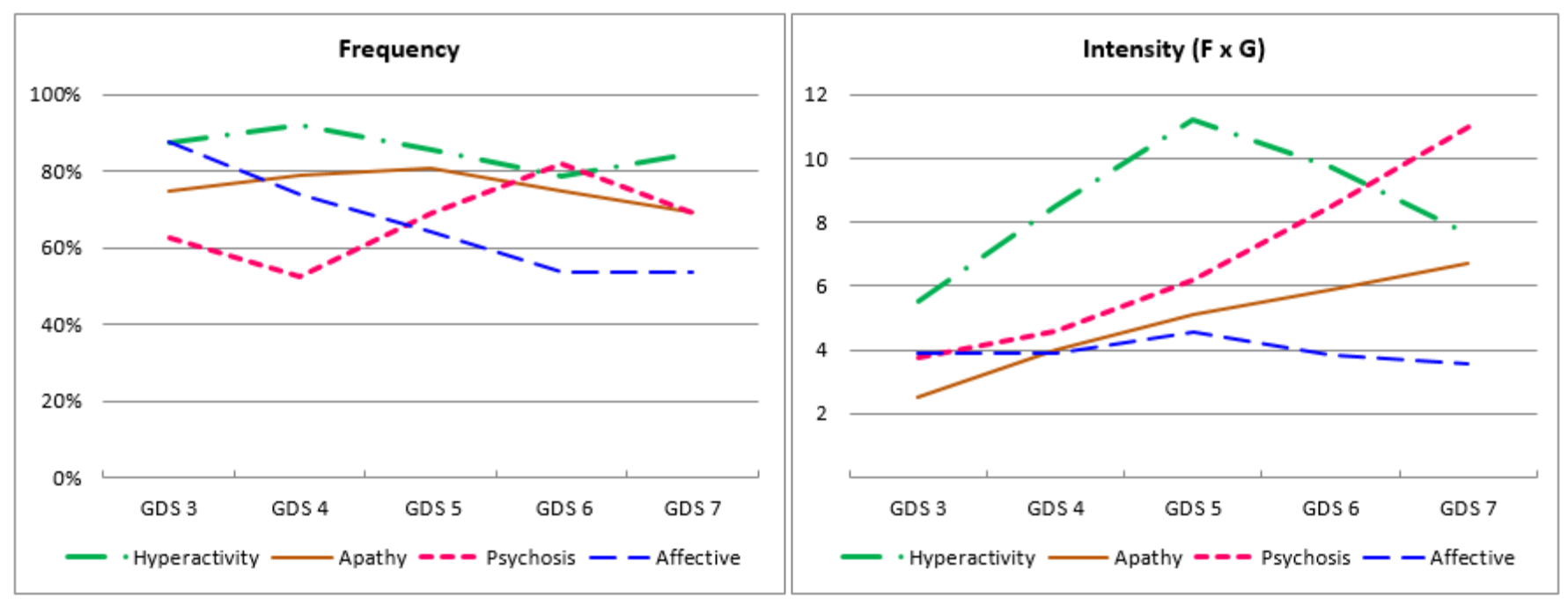

\section{Figure 7}

Frequency and intensity of neuropsychiatric subsyndromes based on the GDS stage of dementia. Legend: GDS: Global Deterioration Scale 


\section{Supplementary Files}

This is a list of supplementary files associated with this preprint. Click to download.

- Additionalfile1.DistributionofneuropsychiatricsymptomsbysexagegroupandGDSstagebasedontheintensityofsymptoms.docx

- Additionalfile2.Prevalenceofneuropsychiatricsymptomsandsubsyndromesinpatientswithdementiaincludedinthestudy.docx

- Additionalfile3.Intensityofsymptomsandneuropsychiatricsubsyndromesinpatientswithdementiaincludedinthestudy.docx

- Additionalfile4.FrequencyandintensityofneuropsychiatricsymptomsbasedontheprogressionofdementiaGDSstage.docx

- Additionalfile5.FrequencyandintensityofsignificantneuropsychiatricsymptomsNPI4basedontheprogressionofdementiaGDSstage.docx

- Additionalfile6.FrequencyandintensityofneuropsychiatricsubsyndromesbasedontheprogressionofdementiaGDSstage.docx 